\title{
TURISMO E DESENVOLVIMENTO URBANO NA REGIÃO METROPOLITANA DA BAIXADA SANTISTA: o caso de Bertioga
}

\section{TOURISM AND URBAN DEVELOPMENT IN THE REGION BAIXADA SANTISTA METROPOLITAN: The case of Bertioga}

\author{
A. Lenimar Gonçalves Rios \\ Observatório Socioespacial da Baixada Santista - Universidade Católica de Santos, Brasil
}

lenimar.rios@gmail.com

\begin{abstract}
O artigo focaliza os efeitos do turismo de segunda residência sobre cidades litorâneas e a função das normas jurídicas na configuração do espaço urbano. Tendo como estudo de caso Bertioga, na Região Metropolitana da Baixada Santista - RMBS, analisa o processo de uso e ocupação do solo e o papel dos planos diretores na distribuição socioespacial da população residente, tendo por base pesquisa bibliográfica e documental. Conclui que, no município estudado, as normas legais historicamente aplicadas, fundadas no zoneamento convencional, não foram capazes de superar impasses que dificultam o desenvolvimento inclusivo e ambientalmente sustentável.
\end{abstract}

Keywords: turismo, segunda residência, urbanização, legislação urbanística.

Linha de investigação: 2: Cidade e Projeto

Tópico: Estudos Metropolitanos e Territoriais.

\begin{abstract}
The article focuses on the effects of second-residence tourism on coastal cities and the function of legal norms in the configuration of urban space. Having as a Bertioga case study, in the Metropolitan Region of Baixada Santista - RMBS, analyzes the process of land use and occupation and the role of the masters plans in the socio-spatial distribution of the resident population, based on bibliographic and documentary research. It concludes that, in the municipality studied, the historically applied legal standards, founded on conventional zoning, were not able to overcome impasses that hinder inclusive and environmentally sustainable development.
\end{abstract}

Keywords: tourism, second residence, urbanization, urban legislation.

Research line: 2: City and Project

Topic: Metropolitan and Territorial Studies. 


\section{XII $\mathbf{S A}$ A O PAULO15 17 LISBOA $25 \sim 26$ JUN 2020}

\section{Introdução}

O presente artigo trata do turismo de segunda residência, abordado sob a ótica dos impactos urbanos e da função do direito urbanístico na construção do padrão de ocupação de municípios litorâneos.

Para desenvolver o trabalho foi estudado o município de Bertioga, localizado na Região Metropolitana da Baixada Santista - RMBS, cuja economia apoia-se exclusivamente no turismo de veraneio, modalidade segunda residência, fatores que geram vulnerabilidades estruturais, com repercussões na configuração socioespacial do território. Não obstante, a imagem do município está fundada num discurso que enfatiza sua excelência ambiental, em que pesem as dificuldades de controle da ocupação que gera degradação ambiental. Historicamente, o ordenamento jurídico do município não apenas tem sido incapaz de deter as desigualdades sócioterritoriais e os impactos delas decorrentes, como tem atuado como elemento de exacerbação de conflitos ambientais.

Partindo do entendimento de que a legislação urbanística legitima o interesse de promotores imobiliários, o trabalho tem como objetivo compreender os mecanismos que originam essa situação. Assim sendo, a pesquisa buscou responder três questões: como as regras de uso e ocupação do solo moldaram o desenvolvimento urbano de Bertioga? como atuam no aprofundamento das desigualdades socieoespaciais do município? é possível, através de marcos legais, reorientar o uso e ocupação do solo visando redução das disparidades sócioterritoriais?

O artigo está assim estruturado: na seção 1 é apresentada fundamentação teórica sobre cidades periféricas e cidades turísticas, a função da legislação urbanística e seus principais instrumentos de planejamento. $\mathrm{Na}$ seção 2 é estudada a RMBS com vistas a contextualizar Bertioga e na seção 3 é analisado o processo de desenvolvimento urbano do município, à luz dos planos diretores que orientaram o uso e ocupação do solo a partir dos anos 1960. Nas Considerações Finais apontam-se dispositivos capazes de evitar uso e ocupação do solo desconformes.

\section{Cidade, turismo de segunda residência e legislação urbanística}

Formadas no contexto do capitalismo periférico, as cidades brasileiras carregam aspectos estruturais decorrentes dos baixos salários e de relações de trabalho onde predomina a informalidade, que se expressam no espaço urbano por clivagens econômicas, sociais e políticas.

As cidades turísticas são [...] locus da produção e do consumo do produto turístico" (Frattuci, 2000:122), entendido como o conjunto de atrativos ligados ao lazer (recursos naturais, infraestrutura, equipamentos, serviços etc.). Embora sejam chamadas a atender demandas distintas das demais cidades, as turísticas se desenvolvem sob as mesmas condições gerais, com destaque para a apropriação social desigual do solo, que ao não oferecer habitação digna torna-se entrave para o desenvolvimento urbano sustentável.

Para Sachs (2008) a esfera social é primordial ao desenvolvimento sustentável, dimensão que é indissociável da ideia de inclusão justa, por ele definida como a inclusão pelo trabalho decente. Definido pela Organização Internacional do Trabalho - OIT, decente é o trabalho exercido em condições de liberdade e remuneração que garantam nível de bem-estar aceitável para o trabalhador e sua família. (Costa, 2010)

$\mathrm{Na}$ esfera do urbano, o desenvolvimento é sustentável se supera as desigualdades socioespaciais resultantes dos baixos salários e da informalidade da mão de obra, condições que negam à maior parte da população direito pleno à cidade, afastando-a para áreas periféricas distantes e ambientalmente frágeis. 


\section{XII $\mathbf{S A}$ A O PAULO15 17 LISBOA $25 \sim 26$ JUN 2020}

Nas cidades de veraneio, que têm a segunda residência como modalidade predominante de hospedagem, os efeitos se agravam, pois à baixa remuneração alia-se a redução das oportunidades de trabalho, que se esvaem ao fim das temporadas com a debandada dos turistas. Intermitência de trabalho e baixos salários combinados com alto preço dos imóveis, agrava a irregularidade e precariedade urbana e habitacional.

Definida como "[...] um alojamento turístico particular utilizado temporariamente nos momentos de lazer por pessoas que tem seu domicílio permanente em outro lugar." (Tulik, 2001:21), a segunda residência é a principal modalidade de hospedagem nas cidades litorâneas brasileiras.

No Brasil, a urbanização calcada na segunda residência cresceu no pós-guerra, momento que coincide com a introdução de mecanismos legais de planejamento urbano. Assiste-se a [...] ascensão da legislação como instrumento por excelência do planejamento" (Feldman, 2001: 6).

O zoneamento converteu-se no principal instrumento legal de controle do uso e ocupação das cidades, dentro de uma concepção tecnocrática, que garante padrões que valorizam as áreas de interesse do mercado imobiliário e alimentam a especulação imobiliária. A propósito, Maricato (2010) destaca que, centrada no zoneamento, a legislação urbanística no Brasil construiu cidades ignorando que o mercado imobiliário atende minorias e desta forma promove segregação sócioterritorial.

A possiblidade de rompimento com o segregacionismo do zoneamento tornou-se real com a Constituição Federal de 1988, que ao estabelecer que a propriedade urbana deve atender ao interesse coletivo forneceu instrumentos de condicionamento do direito de propriedade à função social.

A Função Social da Propriedade, um dos pilares da política urbana contidos na Constituição, "acarreta a imposição ao proprietário de deveres de ação" (Levin, 2008:31), os quais deverão estar definidos no Plano Diretor, a quem cabe "estabelecer os limites e obrigações para o exercício da propriedade urbana" (Denaldi et al, 2015: p.15). Assim, o caráter impositivo possibilita regular não somente o uso e a ocupação do solo, como faz o zoneamento, mas permite ir além, tratando a propriedade como interesse comum e não como objeto de especulação. Para tanto, se apresentam os instrumentos regulamentados pelo Estatuto da Cidade, especialmente Zonas Especiais de Interesse Social (ZEIS), Parcelamento, Edificação, Utilização Compulsória de imóveis vazios, não utilizados e subutilizados (PEUC), IPTU Progressivo no Tempo.

As quase duas décadas de vigência do Estatuto da Cidade revela que grande parte dos gestores municipais se eximem quanto a aplicação de seus principais instrumentos (Denaldi, 2015). Quando adotados, verifica-se relação tensa com os agentes produtores do espaço urbano no momento da implementação das novas ferramentas.

\section{Turismo na Região Metropolitana da Baixada Santista}

Situada no litoral do Estado de São Paulo, a RMBS é formada por 9 municípios: Santos, São Vicente, Cubatão, Guarujá, Praia Grande, Mongaguá, Itanhaém, Peruíbe e Bertioga (figura 1) 


\section{XII $\quad$ SÃOPAULO15 P $17 \cdot$ LISBOA $25 \sim 26$ JUN 2020

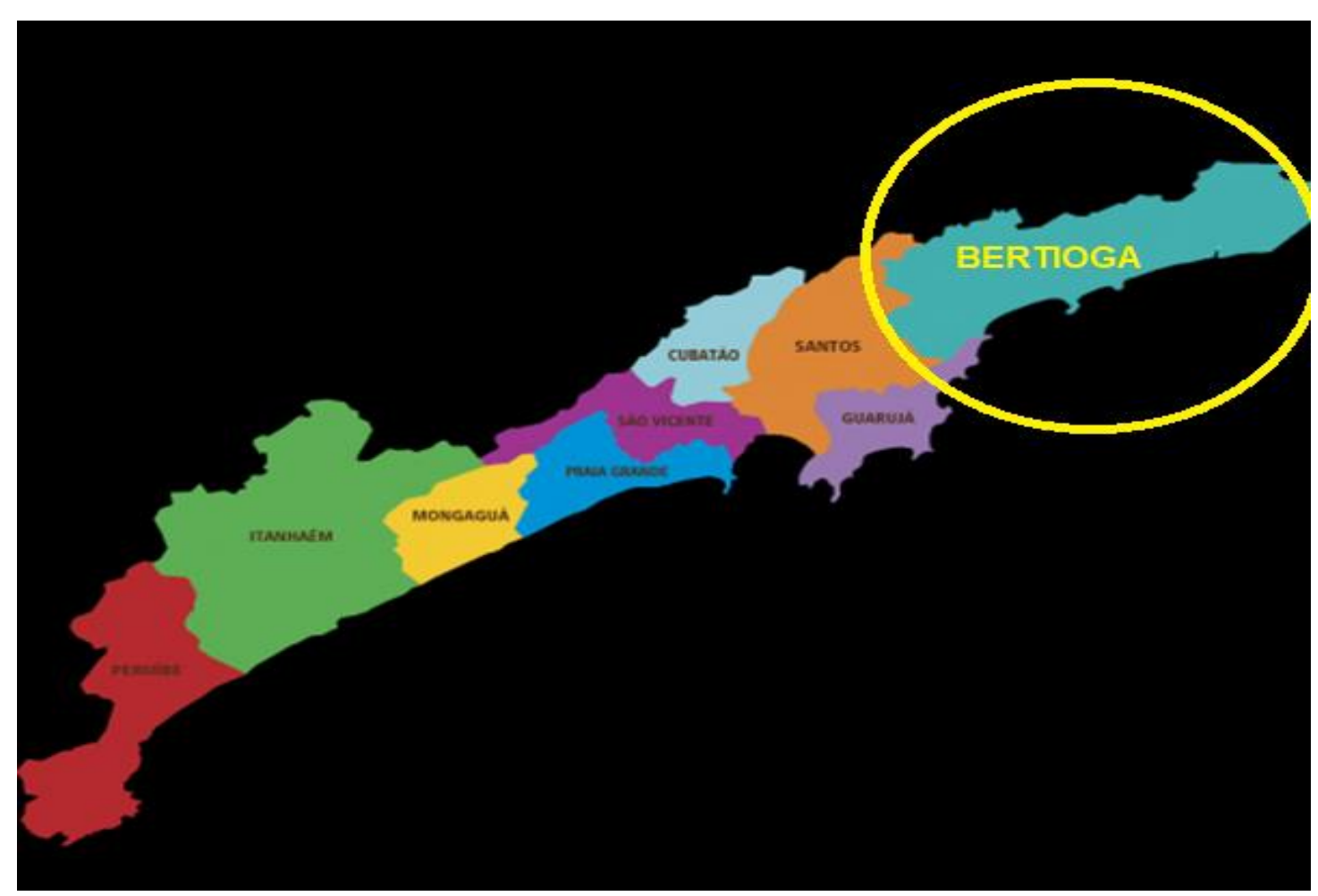

Figura 1. Região Metropolitana da Baixada Santista - RMBS. Fonte: Agência Metropolitana da Baixada Santista - AGEM.

A economia regional apoia-se no porto de Santos, o mais importante complexo portuário da América do Sul, no polo petroquímico-siderúrgico de Cubatão e na atividade turística balneária, presente nos municípios litorâneos e que recebem anualmente milhões de visitantes.

Santos, cidade polo, forma com São Vicente, Guarujá e Cubatão os municípios centrais da região que se estende para o sul com Praia Grande, Mongaguá, Itanhaém e Peruíbe e para o norte com Bertioga.

O desenvolvimento do turismo na região ocorreu em dois períodos: durante o ciclo do café, quando floresceu em Santos e Guarujá e no pós-guerra, com o turismo de massas, que induziu a urbanização dos municípios situados ao sul e ao norte da área central.

\subsection{Municípios centrais - turismo do café e turismo de massas}

Fundamental para ligar as áreas produtoras de café com o porto, a ligação entre São Paulo e Santos por ferrovia, no final do século XIX, transportou também famílias abastadas do planalto para descanso e lazer nas praias de Santos e Guarujá. Em Santos, muitas chácaras (onde moradores locais passavam fins de semana) cederam espaço a palacetes construídos pela burguesia cafeeira e a hotéis. Em Guarujá, foi erguido empreendimento turístico, a Vila Balneária, assim como residências de veraneio na Praia de Pitangueiras.

Com a queda da hegemonia cafeeira, muitos palacetes transformaram-se em pensões, onde, ao invés das famílias abastadas "[...] iam passar seus dias de folga as famílias da classe média e mesmo operária do planalto" (Araújo, 1965:p. 40). 


\section{SÃOPAULO15 17 LISBOA $25 \sim 26$ JUN 2020 \\ Seminário Internacional de \\ Seminario Internacional de Investigação em Urbanismo Investigación en Urbanismo}

O advento do turismo de massas foi fruto do processo de industrialização do pós-guerra que ampliou a classe média e possibilitou a aquisição de residências de uso ocasional em cidades próximas aos grandes centros, acessáveis por automóvel.

Na RMBS, o reforço da conexão São Paulo-Santos através da rodovia Anchieta, construída para atender necessidades do porto e do polo petroquímico-siderúrgico de Cubatão, fez chegar às praias a classe média promovida socialmente e em busca de temporadas à beira-mar.

O mercado imobiliário deu conta de atender essa demanda, lucrando com o máximo aproveitamento construtivo dos terrenos das orlas para produção em larga escala de apartamentos de veraneio. No lugar dos casarões e hotéis construíram-se prédios de apartamentos. Pesquisa realizada por Seabra (1979) contabilizou no final dos anos 1940 a existência de 15 edifícios na orla de Santos, cujos apartamentos tinham sido adquiridos majoritariamente por paulistanos. Cartões postais da época mostram que 0 incipiente processo de verticalização também atingia as praias de São Vicente e Pitangueiras em Guarujá.

A metamorfose da paisagem das praias foi rápida. Em menos de trinta anos consolidou-se em Santos, São Vicente e Guarujá o que Seabra (1979) denominou de 'muralha junto ao mar' (figura 2). Consolidou-se também a verticalização como nova tipologia de ocupação e a segunda residência como modalidade de uso do solo das orlas.

Essa linha de arranha-céus [...] constitui um novo tipo de ocupação do espaço urbano, agora no sentido vertical. Esses prédios de apartamentos representam não só o mais recente tipo de ocupação das praias santistas, como o mais representativo de uma das quatro funções da cidade: o veraneio. (Araújo, 1965:40)

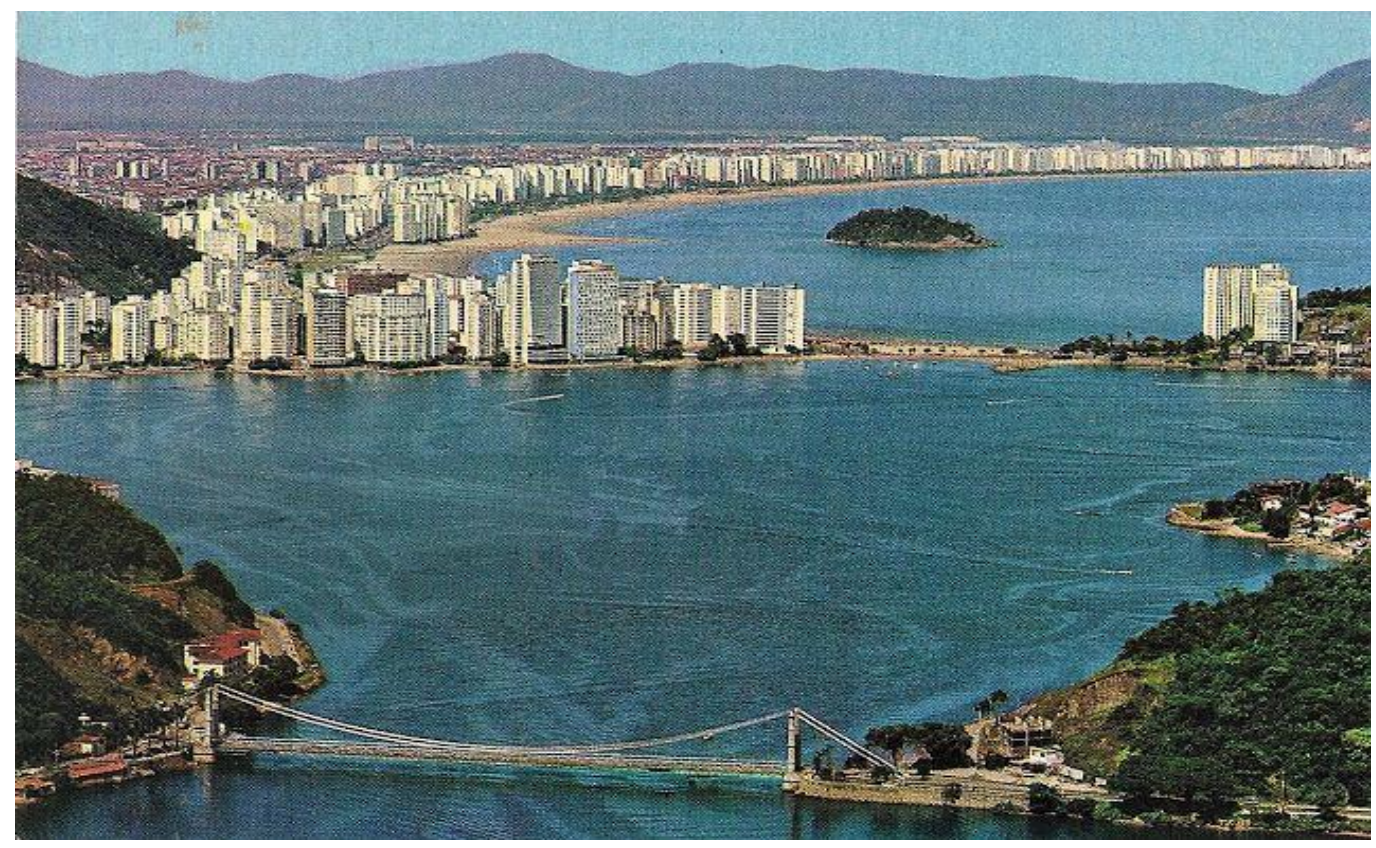

Figura 2. Orla de São Vicente e Santos - anos 1970. Fonte: cidades sem postais, 


\section{XII $\quad$ SÃOPAULO15 P $17 \cdot$ LISBOA $25 \sim 26$ JUN 2020

O esgotamento do mercado de segundas residências, nos anos 1960, redirecionou a produção imobiliária para atender residentes fixos.

"[...] produzia-se agora para uma demanda local, com poder aquisitivo suficiente para consumir habitações de três dormitórios e mais, em edifícios de até um apartamento por andar". (Seabra, 1979:p: 81).

Essa inflexão do mercado deu forma a aspecto estrutural que diferencia Santos e São Vicente dos municípios não centrais: por serem ocupadas majoritariamente por residentes fixos, alguns impactos decorrentes da sazonalidade do turismo balneário ficam amenizados, uma vez que a infraestrutura, os equipamentos e serviços públicos e privados utilizados pelos turistas são os mesmos da população local.

\subsection{Municípios não centrais - turismo de massas e urbanização}

A expansão da modalidade segunda residência para fora da área central foi induzida pela abertura de ligações da região com o sul e com o norte do país. Pelo sul, a Rodovia Padre Manoel da Nóbrega (1961), conectou a via Anchieta com Praia Grande, Mongaguá, Itanhaém e Peruíbe. Pelo norte, as rodovias Manoel Hypólito do Rego (Rio-Santos) e a Mogi-Bertioga consolidaram a ligação de Bertioga com municípios do litoral e diretamente com a Grande São Paulo.

A urbanização desses municípios, que até o advento do turismo eram economias rurais, foi marcada pelo esgotamento da demanda de turistas de maior renda - que a essa altura procuravam o litoral norte paulista, mais valorizado paisagística e ambientalmente - e cresceram incorporando clientela de renda inferior à que moldou o veraneio nos centrais. Referindo-se ao padrão das segundas residências de Praia Grande e Mongaguá, Magalhães (1965: 71) sublinha que [...] corresponde a uma área balneária de categoria média inferior ou mesmo modesta".

Os novos municípios se desenvolveram sobre a porção continental, uma estreita faixa de planície entre a Serra do Mar e o oceano. As rodovias dividem o território em duas porções. Com isso delimitam nos municípios a área de domínio das segundas residências e dos moradores de alto poder aquisitivo, entre a praia e a rodovia, e o território dos moradores fixos e dos segmentos de baixa renda entre a rodovia e a Serra do Mar

Na orla oceânica, recurso natural que dá significado à urbanização dos municípios, desenvolveu-se a mesma tipologia verticalizada das praias de Santos, São Vicente e Guarujá. No restante, em direção à Serra do Mar a ocupação é dispersa.

Ao contrário dos municípios centrais, onde o turismo se somou às atividades portuária e industrial, os não centrais apoiam-se exclusivamente no veraneio modalidade segunda residência, com intensa sazonalidade e consequente ociosidade de infraestrutura e serviços nas áreas de predomínio de segundas residências.

A ociosidade da infraestrutura e serviços instalados decorre da alta incidência de imóveis de uso ocasional, que superam os de uso permanente em todos os municípios, exceto Peruíbe que, mesmo assim, apresenta alto índice quando comparado com os centrais (tabela 1).

\begin{tabular}{|l|c|c|}
\hline MUNICÍPIO & PERMANENTE & OCASIONAL \\
\hline Santos & $81,70 \%$ & $11,33 \%$ \\
\hline São Vicente & $82,62 \%$ & $9,43 \%$ \\
\hline Guarujá & $61,81 \%$ & $33,69 \%$ \\
\hline
\end{tabular}




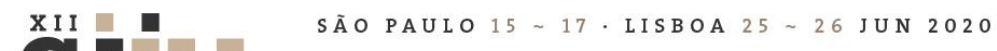

Seminário Internacional de Investigação em Urbanismo

Seminario Internacional de Investigación en Urbanismo

\begin{tabular}{|l|c|c|}
\hline Cubatão & $93,68 \%$ & $0,56 \%$ \\
\hline Praia Grande & $\mathbf{4 1 , 7 3 \%}$ & $\mathbf{5 2 , 4 4 \%}$ \\
\hline Mongaguá & $\mathbf{3 4 , 9 0 \%}$ & $\mathbf{6 0 , 5 5 \%}$ \\
\hline Itanhaém & $\mathbf{4 2 , 1 1 \%}$ & $\mathbf{5 1 , 8 9 \%}$ \\
\hline Peruíbe & $\mathbf{4 8 , 0 4 \%}$ & $\mathbf{4 4 , 1 6 \%}$ \\
\hline Bertioga & $\mathbf{3 7 , 8 2} \%$ & $\mathbf{6 2 , 1 8 \%}$ \\
\hline
\end{tabular}

Tabela 1. RMBS - Domicílios de uso permanente e uso ocasional - 2010.Fonte: Elaboração Instituto Polis, 2012 a partir do Censo Demográfico IBGE 2010.

As áreas que concentram domicílios de uso ocasional são as mais bem servidas de infraestrutura e equipamentos urbanos em contraposição às de população fixa, caracterizadas por carências. Estudos efetuados por Souza (2018), com base no Censo Demográfico IBGE 2010 (dados agregados por setores censitários), revelam que as áreas servidas por esgoto sanitário cobrem 15,39\% do território dos setores censitários e concentram $61,46 \%$ dos imóveis de uso ocasional. Nas áreas de menor cobertura de esgotos, que correspondem a $84,61 \%$ do território estudado é onde está a maior parte dos imóveis de população fixa $(56,09 \%)$

A prevalência das segundas residências é o aspecto estrutural que define o perfil econômico dos municípios não centrais, pois quanto maior o número de domicílios de uso ocasional maior a dependência econômica do turismo balneário. Como mostra Aledo et al (2007) ao estudar municípios espanhóis, a sazonalidade somada aos baixos gastos dos turistas de segunda residência dificulta a criação de cadeias produtivas capazes de proporcionar empregos. As disparidades estão retratadas no gráfico 1 que mostra a participação dos municípios na composição dos empregos. A exceção fica com Praia Grande, cujo perfil vem se alterando nas últimas décadas com o crescimento de população residente.

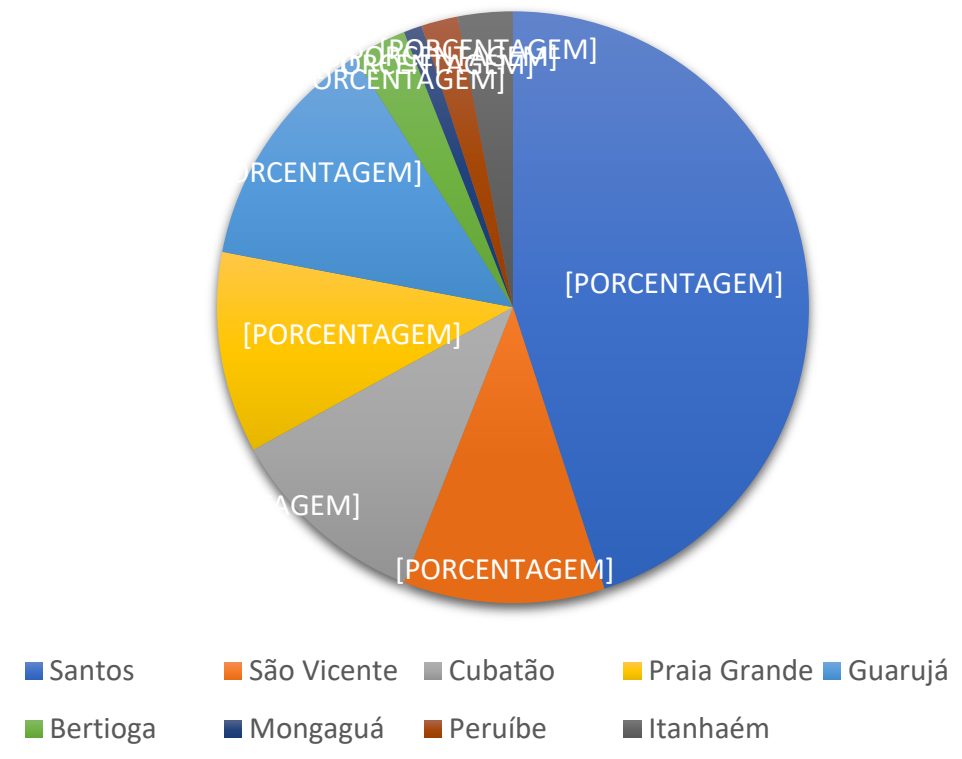

Gráfico 1. Participação dos municípios na geração total de empregos da RMBS em 2011. Elaboração própria com base em dados da AGEM, 2014. 


\section{XII $\square$ SÃOPAULO15 17 LISBOA $25 \sim 26$ JUN 2020 \\ Seminário Internacional de \\ Seminario Internacional de Investigação em Urbanismo Investigación en Urbanismo}

A pobreza da população fixa combinada com alto preço dos imóveis produziu quadro generalizado de exclusão sócioterritorial, concentrada nas bordas de todos os municípios, em áreas ambientalmente frágeis e que não interessam ao mercado imobiliário, fato alimentado e legitimado pela legislação urbanística que moldou a configuração socioespacial (figura 3).

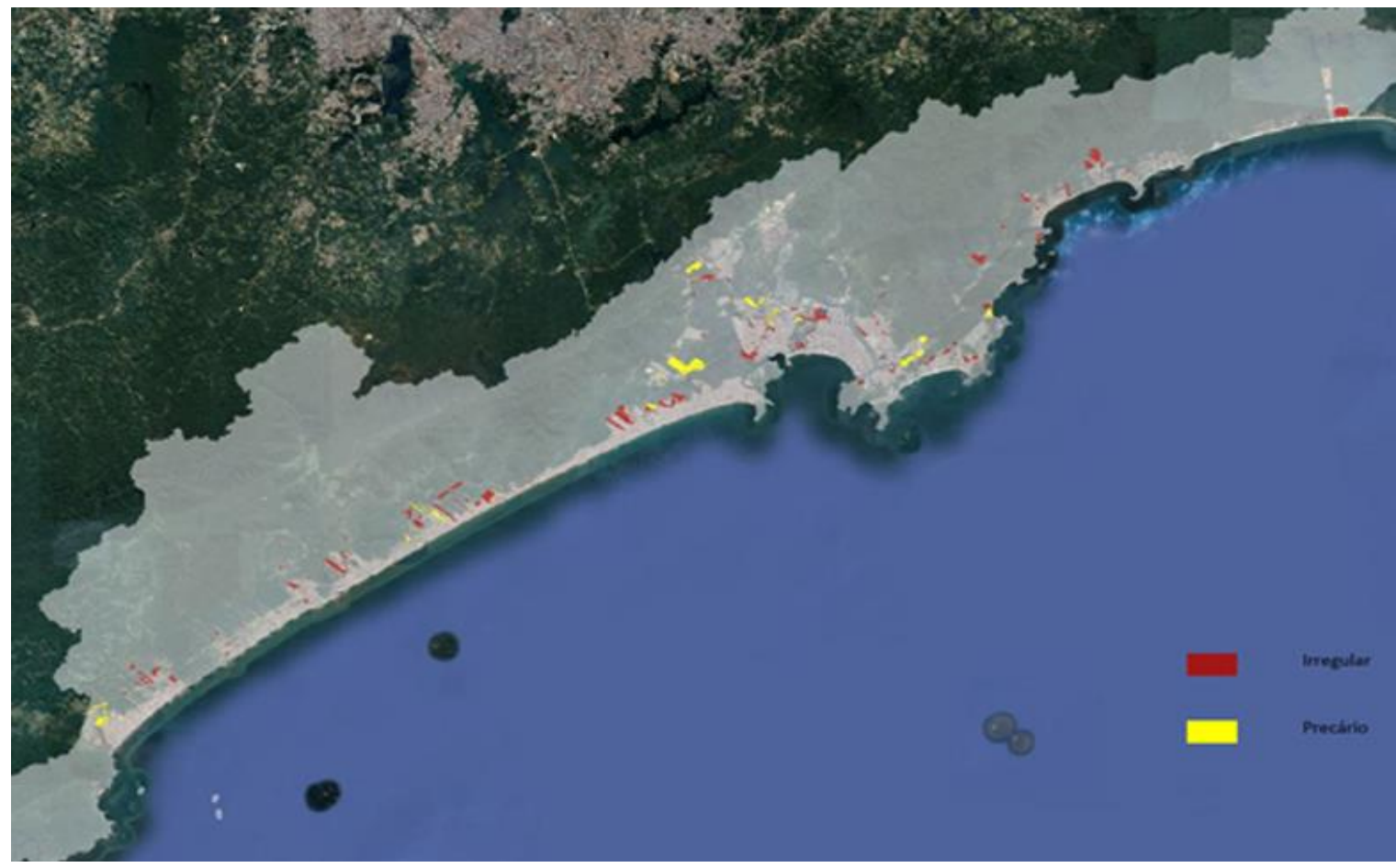

Figura 3. Distribuição dos assentamentos irregulares e precários na RMBS. Fonte: Instituto Polis, 2012

Através do zoneamento a legislação garantiu, com discurso de respeitar a 'vocação natural dos municípios', reserva de áreas de excelência junto à orla oceânica (Carriço, 2000). Consolidadas como territórios dos domicílios de veraneio e com parâmetros restritivos, ditam os valores dos imóveis para o restante da área urbana. No espaço entre a rodovia e a serra as exigências são mais flexíveis, porém não suficientes para contemplar os segmentos de baixa renda.

Essa situação é agravada pela não adoção de novos instrumentos de gestão oferecidos pelo Estatuto da Cidade, capazes de garantir a função social da propriedade e atuar na dinâmica urbana de modo a combater a especulação imobiliária e a segregação socioespacial.

Cubatão e Bertioga não atualizaram seus planos, em vigor desde 1998, embora, assim como os demais tenham regulamentado ZEIS. Em relação ao PEUC e IPTU Progressivo no Tempo, apenas Santos, Guarujá, Itanhaém e Peruíbe incorporaram os instrumentos a seus planos, mas exceto Santos, que regulamentou sua aplicação, nos demais o instrumento carece de efetividade, resumindo-se a mera citação na legislação.

Bertioga apresenta similaridades com os demais municípios não centrais e peculiaridades que a diferenciam, como será visto a seguir. 


\section{SÃOPAULO15 17 LISBOA $25 \sim 26$ JUN 2020

\section{O modelo de ocupação de Bertioga à luz da legislação urbanística}

Localizada na porção continental da RMBS, Bertioga ocupa a planície entre o oceano e a Serra do Mar. A planície, que se estende por 45km com largura média de cerca de 6km (Bertioga, 2017), é recortada por cinco praias, separadas por morros e costões rochosos (figura 4).

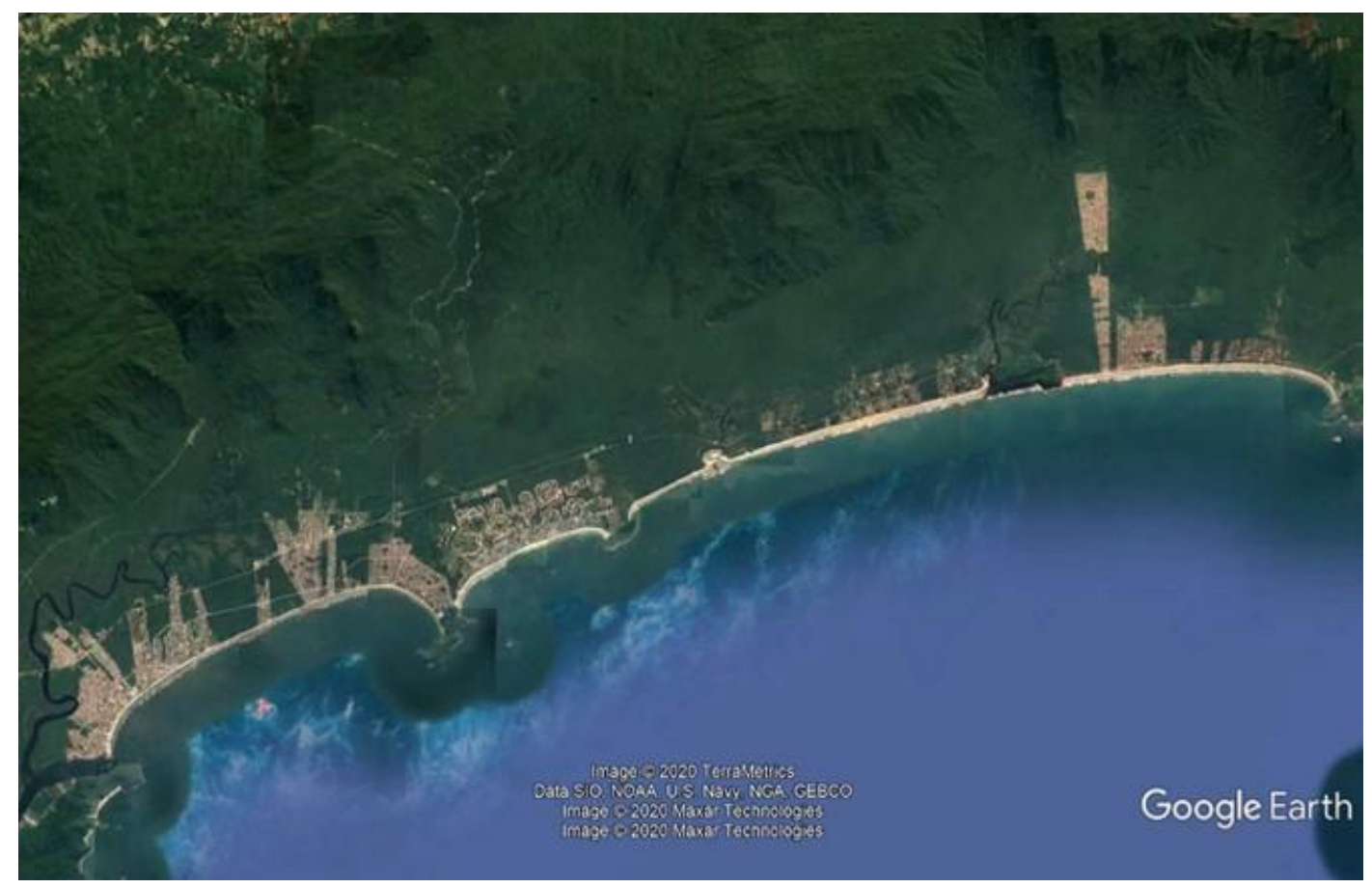

Figura 4. Bertioga - planície e orla oceânica. Fonte: Elaboração própria sobre imagem do Google Earth, 2015

Com população estimada em 59.297 habitantes para 2017 (IBGE, 2018), apresenta o mais alto índice de crescimento regional, com previsão de incremento demográfico de 19,55\% para o período 2010-2017 (IBGE, 2018).

A evolução urbana e a legislação urbanística, atravessaram 3 períodos: antes e após a entrega da rodovia Rio-Santos ao tráfego de veículos (1980) e após a emancipação político administrativa de Santos (1992).

O primeiro período (1950-1980) teve como marco a instalação, em 1948, da colônia de férias do Serviço Social do Comércio - SESC, na praia da Enseada. Apesar da dificuldade de acesso, feito por barcas que ligavam com Santos e uma estrada precária que passava por Guarujá, a presença do SESC animou empresas a lotearem terras na Enseada, destinando-as a segundas residências. Ocupando de maneira predatória o sítio original, sem saneamento, desmatando áreas de restinga e avançando sobre várzeas de rios, os loteamentos distribuíram-se de forma fragmentada, mas sempre com suas vias ligando os lotes com as praias.

O primeiro dispositivo legal de ordenamento, a Lei Municipal 3.532/1968 (Planejamento Físico de Bertioga), disciplinava o uso e ocupação da porção situada entre o mar e a Serra, dividida em Área Urbana e de Expansão Urbana. 


\section{SÃOPAULO15 17 LISBOA $25 \sim 26$ JUN 2020

Para a Área Urbana, entre a orla e a rodovia (ainda em projeto), estabelecia os mesmos critérios de zoneamento adotados para Santos: faixas paralelas à praia definidas como Zona Turística, Zona Residencial e Zona Mista.

A partir de então a rodovia Rio-Santos passou a definir, nas legislações subsequentes, a fronteira da área urbana.

O zoneamento, por sua vez, inaugurou uma característica que, com variantes, subsiste até hoje nos dispositivos legais: o espaço urbano junto a orla reservado para fins residenciais e de veraneio, com exigências zonais mais elevadas, que diminuem à medida que se afasta da praia. Define-se, assim, o princípio de zonas de excelência que ditarão os valores imobiliários a partir da orla. No outro extremo, próximo à rodovia, os critérios, bem flexíveis, permitiam parcelamentos para moradias econômicas, porém compartilhando espaço com atividades incômodas como armazenagem, indústrias, postos de combustíveis. A dimensão mínima dos lotes nessa zona, fixada em $250 \mathrm{~m}^{2}$, tornava inacessível sua compra por segmentos de baixa renda.

A inauguração da Rio-Santos no trecho de Bertioga impulsionou o segundo período de crescimento, marcado pela reorientação do modelo de desenvolvimento urbano. Temia-se que a ocupação predatória da Enseada se replicasse nas demais praias, ainda intocadas. Estas sofreriam efeitos devastadores com a aplicação de diretrizes legais em vigor, que reproduziriam em Bertioga o desvalorizado modelo santista e dos municípios do eixo sul, com destruição da paisagem e poluição das praias. Projetava-se introduzir em Bertioga o alto padrão que se consolidava no litoral norte paulista.

O mercado imobiliário antecipou-se às alterações legais lançando o projeto Riviera de São Lourenço, que inaugurou a fase dos megaempreendimentos, em que promotores parcelam a terra e investem em saneamento básico para garantir qualidade das praias. O desenho urbano, apresentado como diferencial porque liberava espaços verdes (ver crítica em Souza [2018]), utilizou parâmetros mais restritivos do que os estabelecidos pelo Planejamento Físico de Bertioga, em vigor quando de sua tramitação na prefeitura. Os coeficientes de aproveitamento, porém, seguiam os estabelecidos, com verticalização da faixa da orla.

Pode-se dizer que o projeto Riviera materializou o discurso da preservação ambiental como oportunidade de valorização dos investimentos, ante a depreciação do modelo instaurado na RMBS.

Para dar guarida aos novos padrões, o Código de Uso do Solo e Proteção dos Recursos Naturais de Bertioga (Lei 4.078/1976) rompeu com as diretrizes do ordenamento em vigor, mas não com os fundamentos que moldaram o modelo excludente. Se por um lado consagrava na lei municipal diretrizes de preservação dos recursos naturais e concentrava construções verticalizadas em eixos perpendiculares à praia, evitando paredão junto à orla, por outro, através de altas exigências quanto dimensão mínima de lotes, exacerbava o modelo de valorização dos imóveis a partir da orla. Não previa, em nenhuma zona, a possibilidade de moradias econômicas. O megaempreendimento Costa do Sol, na praia de Guaratuba, é o modelo resultante dessas regras: lotes de grandes dimensões combinados com baixos índices de ocupação e coeficientes de aproveitamento.

A emancipação político administrativa de Bertioga (até então distrito de Santos), em 1992, ocorreu num contexto urbano afetado por migrações atraídas pela construção civil e pelo aumento de irregularidade e precariedade urbanística e habitacional. Com crescimento ainda hoje fortemente impulsionado por migrações, o município contabiliza mais de $50 \%$ da população residente originária do nordeste e da cidade de São Paulo, dos quais $46 \%$ declararam ter migrado por motivo de trabalho (Bertioga, 2018).

O Plano Diretor pós emancipação, elaborado por técnicos da prefeitura com a participação de representantes da Associação de Engenheiros e Arquitetos de Bertioga, na justificativa que acompanhou o projeto de lei 


\section{XII $\square$ SÃOPAULO15 $\sim 17 \cdot$ LISBOA $25 \sim 26$ JUN 2020

quando de seu envio à Câmara Municipal, debitou as dificuldades de respostas aos problemas urbanos que se avolumavam às restrições do Código em vigor. Avaliou que, ao não oferecer condições de adensamento construtivo na maior parte do território e nem permitir habitação popular, num contexto de carência de empregos e ineficácia do Estado, alimentava ocupações irregulares e de áreas de preservação. (Bertioga, 1994)

Atribuía, também, parcela de responsabilidade às leis ambientais de âmbito federal e estadual as quais, na interpretação dos técnicos, ao imporem restrições para ocupação do solo alimentariam usos indevidos com degradação de manguezais, matas ciliares dos rios, vegetação de restinga, a flora e a fauna (Bertioga, 1994). De fato, reconhecendo a vulnerabilidade dos ecossistemas, a legislação ambiental coloca sob proteção $88,1 \%$ da área do município. Dos $11 \%$ restantes a maior parte está ocupada, sobrando poucos espaços para expansão urbana.

Em vigor desde 1998, o Plano Diretor de Desenvolvimento Sustentável (PDDS), Lei 315/1998 e a Lei de Uso e Ocupação do Solo (LUOS), Lei 317/1998, se propõem responder os desafios mantendo, em linhas gerais, as mesmas diretrizes dos dispositivos anteriores quanto ao padrão de uso e ocupação. Porém, diferentemente da lei anterior, a nova LUOS estabelece dimensões mínimas menores para os terrenos, inclusive lote mínimo de $125 \mathrm{~m}^{2}$ para parcelamentos de interesse social.

Esses parâmetros, reproduzidos desde 1968 pelos dispositivos legais, influenciam a valorização imobiliária no município, hoje entre as mais altas do país. Segundo pesquisa da Fundação Instituto de Pesquisas Econômicas - FIPE realizada em 2015, em Bertioga os imóveis valorizaram 34,7\%, maior índice entre 100 cidades brasileiras pesquisadas. No mesmo período, os imóveis em Santos valorizaram 1,4\% e em Guarujá $3,9 \%$. O fenômeno é atribuído à limitada quantidade de áreas ocupáveis e aos imóveis de uso ocasional de alto padrão, sendo que, conforme análise, a Riviera de São Lourenço influencia essa valorização (Bertioga, 2015).

Em contraposição, mais de $70 \%$ da população residente tem baixos rendimentos nominais: $29,2 \%$ na categoria 'sem rendimentos', 27,7\% na faixa de 1 a 2 SMs e 15\% entre $1 / 2$ e 1 SM. (IBGE, 2018)

Baixa renda e alto preço da terra repercutem em precariedade urbanística, bem mais grave em Bertioga, onde $20,56 \%$ do total de domicílios estão em assentamentos precários. Em Praia Grande, Itanhaém, Mongaguá e Peruíbe são $11,10 \%, 4,20 \%, 8,30 \%$ e 3,44\% respectivamente. (IBGE, Censo Demográfico, 2010)

Uma preocupação expressa no Diagnóstico do PDDS refere-se aos loteamentos gravados como irregulares pelas sucessivas leis. Para estes propunha-se regularização sob justificativa de "evitar áreas abandonadas que acabam gerando ocupações desordenadas" (Bertioga, 1994: p 26). Contudo, não há referência a mecanismos de caráter preventivo, que evitem novas ocupações irregulares, apenas a indicação de adoção de ZEIS.

A Lei Complementar 04/2001 instituiu dois tipos: ZEIS 1, para regularizar jurídica e urbanisticamente áreas já ocupadas, sanar situações de risco e adequar condições de habitação. Com a ZEIS 2 as normas visam induzir a ocupação de vazios urbanos utilizando parâmetros especiais para parcelamento, reduzindo custos e indicando áreas preferenciais para urbanização. A lei menciona que dentre os objetivos dos parâmetros especiais está o de estimular proprietários de vazios urbanos a investir em empreendimentos habitacionais. Contudo não há nem no PDDS, nem na LUOS e nem em lei específica dispositivos que deem efetividade a essa intenção, como o instituto do Parcelamento, Edificação Utilização Compulsórios de vazios urbanos (PEUC) e IPTU Progressivo no Tempo.

Considerações finais 


\section{XII $\square$ SÃOPAULO15 $\sim 17 \cdot$ LISBOA $25 \sim 26$ JUN 2020

Sob a égide do turismo de segunda residência, o uso e ocupação do solo nos municípios não centrais da RMBS produziu estruturas urbanas suscetíveis à degradação ambiental, num contexto em que os recursos naturais são objeto de consumo.

A legislação urbanística historicamente desempenhou papel relevante nesse processo ao garantir a valorização imobiliária dos espaços junto às orlas, vazias de população a maior parte do ano e o consequente afastamento dos moradores de menor renda para o interior do território, em direção a áreas legalmente protegidas e/ou de risco

Em Bertioga a legislação urbanística conduziu a modelo similar, mas voltado nas últimas três décadas para clientela de alta renda. A combinação de uso e ocupação do solo restritivos com a limitada oferta de áreas ocupáveis, no contexto de um mercado altamente especulativo, produziu intensa valorização imobiliária, que exacerbou as disparidades sócioterritoriais e a vulnerabilidade de áreas legalmente protegidas.

Em desconformidade com o Estatuto da Cidade, a legislação em vigor espera sanar e evitar ocupações 'desordenadas' apenas flexibilizando, através do zoneamento, os parâmetros de uso e ocupação. Afora as ZEIS, a legislação municipal não incorporou outros instrumentos de caráter impositivo, como PEUC e IPTU Progressivo no Tempo. Portanto, não adotou mecanismos que, combinados com ZEIS, são capazes de dar efetividade ao controle da especulação imobiliária e condições para que a administração municipal planeje a ocupação do espaço urbano com inclusão social.

Enquanto o município não fizer esforço para equacionar as disparidades sociais expressas no território, adotando instrumentos de planejamento que permitam controle mais eficaz do uso e ocupação solo, perdurarão os impasses para proteger os recursos naturais, base da identidade do município, do discurso oficial e da atuação do mercado imobiliário.

As contradições apontadas neste estudo de caso certamente se fazem presentes em outros municípios, apontando a necessidade de novas indagações para análise de situações similares, de maneira a ampliar o conhecimento das transformações urbanas resultantes do turismo balneário de segunda residência e os efeitos territoriais da exclusão social.

\section{Bibliografia}

ALEDO, A.; MAZÓN M. T.; MANTECÓN (2007) A. La insostenibilidad del turismo residencial. In Lagunas, David (coord.) Antropologia y turismo: claves culturales y disciplinares. Mexico: DF.

AGEM - Agência Metropolitana da Baixada Santista (2014). Plano Metropolitano de Desenvolvimento Estratégico - PMDE, 2014 -2020

ARAUJO FILHO, J. R. (1965) As áreas funcionais de Santos in Baixada Santista - aspectos geográficos. V. III, 49-63. São Paulo: EDUSP.

BERTIOGA - PREFEITURA MUNICIPAL (1994) Plano Diretor Participativo - materiais para consulta. Processo 2538/1994 - (2015): Boletim Oficial do Município n. 666. (2018): Diagnóstico e prognóstico para viabilização da revisão do Plano Diretor do município.

CARRIÇO, J. M. (2002). Legislação urbanística e segregação espacial nos municípios da Região Metropolitana da Baixada Santista. Dissertação de Mestrado. São Paulo: FAUUSP

COSTA, M. O. (2010). Trabalho decente segundo a OIT. Jus (on line)

DENALDI, R., CAVALCANTI, C. B., SOUZA, C. V. C. (2015) PEUC e IPTU Progressivo no Tempo: caderno técnico de regulamentação e implementação do Estatuto da Cidade. Brasília: Ministério das Cidades. 


\section{XII $\square$ SÃOPAULO15 $\sim 17 \cdot$ LISBOA $25 \sim 26$ JUN 2020

FELDMAN, S. (2001). Avanços e limites na historiografia da legislação urbanística no Brasil. Revista Brasileira de Estudos Urbanos e Regionais, 4, 33-47.

FRATTUCI, A. C. (2000) Os lugares turísticos: territórios do fenômeno turístico. Revista do programa de PósGraduação em Geografia da UFF (Niterói), 4, 121-133.

IBGE - INSTITUTO BRASILEIRO DE GEOGRAFIA E ESTATíTICA. (2010) Censo demográfico - (2018): Cidades.

INSTITUTO POLIS (2012). Litoral sustentável - desenvolvimento com inclusão social. São Paulo: Instituto Polis-Convênio Petrobrás.

LEVIN, A. (2008). PEUC de imóveis públicos urbanos. Dissertação de Mestrado: São Paulo: PUCSP.

MAGALHÃES, E. D'. (1965). Praia Grande e Mongaguá in Baixada Santista - aspectos geográficos. V. III, 65-77. São Paulo: EDUSP.

MARICATO, E. (2010) O estatuto da cidade periférica, in CARVALHO, C.S e ROSSBACH, C. O Estatuto da Cidade Comentado. São Paulo, Ministério das Cidades. Aliança de Cidades.

SACHS, I. (2008). Desenvolvimento includente, sustentável, sustentado. Rio de Janeiro: Garamont.

SEABRA, O. C. L. (1979). A muralha que cerca o mar: uma modalidade de uso do solo urbano. Dissertação de Mestrado. São Paulo. FFLCH-USP.

SOUZA, R. S. R. (2018). O papel da legislação e das instituições para a conservação da diversidade ambiental e cultural da Baixada Santista. Tese de Doutorado São Paulo. FAU-USP.

TULIK, O. (2001) Turismo e meios de hospedagem - casas de temporada. São Paulo. Roca.

Leis

Planejamento Físico de Bertioga (1968) Lei 3.532 de 16/04/1968. Código de Uso do Solo e Proteção dos Recursos Naturais de Bertioga (1976) Lei 4.078 de 03/12/1976. Prefeitura Municipal de Santos.

Plano Diretor de Desenvolvimento Sustentável (1998). Lei 315 de 29/08/1998. Lei de Uso e ocupação do solo (1998). Lei 317 de 07/10/1998. Lei de ZEIS (2001). LC 04 de 20/12/2001. Prefeitura Municipal de Bertioga

Fontes eletrônicas

http://cidadessempostais.blogspot.com (consulta: 29/06/2017)

periódicos.uff.br (consulta:16/11/2018)

polis.org.br (05/08/2017)

rbeur.emnuvens.com.br (consulta: 23/07/2017)

rua.ua.es (consulta: 21/10/2018)

tede2.pucsp.br (consulta: 08/08/2018)

teses.usp.br (consulta: 22/01/2020)

www.agem.sp.gov.br (consulta: 20/09/2017 e 15/05/2018)

www.bertioga.sp.gov.br (consulta 14/11/2018) 


\section{SÃO PAULO15 17. LISBOA $25 \sim 26$ JUN 2020}

Seminário Internacional de

Seminario Internacional de Investigação em Urbanismo Investigación en Urbanismo

www.ibge.gov.br (consultas: 20/01/2018 e 28/01/2019)

www.jus.com.br (consulta: 05/11/2018)

www.secit.ma.gov.br (consulta: 18/07/2017) 